\title{
ON THE CONNECTION
}

BETWEEN A

\section{LOCAL AFFECTION OF THE LYMPHATIC SYSTEM}

AND

CHYLOUS URINE;

WITH

REMARKS ON THE PATHOLOGY OF THE DISEASE.

BY

H. V. CARTER, M.D. LoND.,

PROFGSSOR OF ANATOMY AND PHYSIOLOGY, BOMBAY MEDICAL COLUEGE.

COMMUNICATED BY

PRESCOTT G. HEWETT, F.R.C.S., SURGEON TO ST. GEORGE'S HOSPITAL.

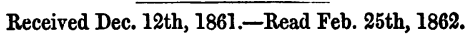

Tнг view now proposed of the hitherto obscure disease characterised by a chylous condition of the urine was first suggested by several interesting cases which presented themselves at the male dispensary attached to the Jamsetjee Jejeebhoy Hospital, under my charge. They are narrated in the order of occurrence, which order serves also to place them in the mutual relation best illustrating the views now brought forward.

There is, first, an instance of well-marked local derangement of the lymphatic system, accompanied by the accumulation of chyle, and its occasional discharge from the cutaneous surface. The urine is unaffected.

The next is a case in which also a local affection of the 
lymphatic vessels and glands is present, and, as well, a frequent external discharge of chyle. But the urine, too, is frequently chylous, in the strict sense of the word.

Lastly, without any external local affection of the lymphatics, the patient presents a striking instance of chylous urine, also intermitting in character.

Case 1.-A Parsee youth, in fair health, attended July 15th, 1859. Suffers from slight fever. The inguinal glands are greatly enlarged, soft and doughy to the touch, but not painful. On the cutaneous surface of the thigh, a few inches below Poupart's ligament, is a small, hardly perceptible pimple, from which there occasionally issues a milky fluid, and sometimes so copiously that in the course of the day a pint has been collected. Pressure just above the spot causes the flow to cease: when the spot itself is compressed the fluid squirts out to some distance, leading to the supposition that there is a small dilated sac behind the orifice. Appetite and diet normal.

History.- Six months since, the discharge spontaneously commenced; it lasted two or three days, and then ceased, pressure having been used : it reappeared after the interval of a month, and again stopped after a few days. The present is the third time the discharge has reappeared. Before it comes on, the glands in the groin become, as he states, tumid, and rather painful : afterwards this ceases.

On August 7th and 3lst there was a copious flow of chyle; in the interval it ceased. The axillary glands on the left side inflamed and suppurated. Health improved under the influence of iodide of potassium.

In September, 1860, he was seen again, and was suffering from slight fever; the inguinal glands were enormously enlarged, and the local discharge continued the same. Health unaffected.

Description of the fluid discharged.-When collected in a tumbler, its resemblance to rich milk is striking : its colour is yellowish or bluish white, but it soon acquires a rather pink tint. It possesses a faint, hardly perceptible odour, 
and a reaction slightly alkaline. A drachm collected in a test-tube coagulates in about five minutes; it separates a few hours afterwards into clot and serum, the latter being milky in appearance : at a later period the whole becomes again fluid. The clot is tolerably firm. On one occasion the patient brought two tumblers filled with chyle, which he had collected during the night. The flow was constant and abundant while it lasted.

Microscopic examination, two hours after removal.-In the fluid were found a universal hazy tint ; groups of minute granules; red blood-corpuscles, some apparently dividing; oil-globules of various sizes; granular corpuscles, from a little above the size of the latter up to $\frac{1}{2000}$ of an inch in diameter, the larger being also nucleated; a few masses of granules.

Further details of the case, and figures illustrating the microscopic appearances, are in my possession, but it will be sufficient to indicate the identity of the fluid discharge with chyle, which the microscope proves.

CaSe 2.-An adult Hindoo became an out-patient August 23rd, 1859, on account of an affection of the scrotum. The skin of this part is corrugated in a peculiar way, thickened, and studded with numerous small tubercles, which are soft to the touch, and, when punctured, freely discharge a chylous fluid. The size of these tubercles (or varicosities) varies from that of a pin's head to that of a pea, or even larger. The inguinal glands on both sides are much enlarged, soft, and doughy to the touch, and they diminish in size under pressure.

History.-Four months since, the scrotum began to enlarge. Native applications were made, and it was only after a time that the peculiar corrugation of the skin appeared. The milky discharge occasionally occurs spontaneously, and it intermits : at present it has been going on for two days, and he reckons to have lost about one pound of fluid daily. It does not issue from any one spot, but from several ; it may be, according to the number and position of the tubercles 
that have burst. When it ceases, and sometimes also during the time the discharge is going on, the urine becomes chylous, and frequently coagulates. Such is his own account. Health indifferent; no appetite. He was afterwards admitted into hospital, and I found that the tumefaction of the inguinal glauds seemed to alternate with the appearance of chyle in the urine. This circumstance was sufficiently established. The parts also became tumefied a short time (two or three hours) after a full meal, and then again subsided. There did not appear to be any regularity in the appearance or disappearance of chyle in the urine.

When normal, the urine was clear, high-coloured, and unaffected by heat or nitric acid. When chylous, its colour was either white, reddish white, or light pink, with a subsequent deposit of pink particles (blood-corpuscles): in the first case a pinkish colour was usually assumed after some exposure to air. Generally the urine coagulated more or less completely, the clot assuming a red colour. Its quantity was considerably increased, and it very readily underwent decomposition. Specific gravity, 1017.

The fluid that escaped from the scrotum was probably chyle, or a mixture of this with lymph. About two drachms were collected in a test-tube, which was then corked. In about two or three minutes, while flowing, the fluid assumed a very decided rose tint, which somewhat increased on further exposure. It coagulated entirely in eight or ten minutes. After an hour or two, when exposed to air, the clot almost immediately changed its colour to blood-red, the milky serum remaining unchanged. On another occasion I found the fluid to coagulate in four or five minutes, and in an hour begin to separate into clot and serum : eight hours afterwards about one sixth of the whole had separated as a milky serum. The clot was slightly red or pink, the uppermost layer, next the air, quite blood-red in colour. During the night the clot dissolved, and all the red particles subsided to the bottom. The change of colour of this man's urine on exposure to air was striking, but far more marked in the chylous fluid : it was almost wonderful to see the bright 
pink colour steal over the surface of the clotted mass, the surface of which in a few minutes resembled blood.

Microscopic examination.-The urine was found to contain, besides blood-corpuscles, \&c., granular cells much larger than these, and showing, on the addition of acetic acid, three or four nuclei in their interior; they were, in short, chylecorpuscles. In the chyle the clot was examined two or three hours after removal, and there were found the molecular base ; a few small granules; red blood-corpuscles, some well-formed, some granular and starred; corpuscles rather larger than these, with colour less decided and margins slightly irregular (they were almost as numerous as the more perfectly formed (?) or darker red corpuscles); others having a mulberry aspect, varying in size and sometimes flattened; lastly, granular corpuscles, $\frac{1}{2700}$ of an inch in diameter, and resembling the lymph-corpuscles of blood. I endeavoured to watch the change of colour under the microscope, but could not detect any cause for it ; red corpuscles were however seen, apparently in various stages of formation. The blood-serum was quite clear.

Various plans of treatment, local and general, the latter including very large doses of gallic acid, were adopted, without producing a favourable effect.

CaSe 3.-A Hindoo youth came to the dispensary, October 21st, 1860. He stated that his urine appeared to be mixed with milk and blood; that this appearance had come on suddenly two years since. On his rising one morning to make water, a large quantity of milky fluid flowed, and so alarmed him that he nearly fainted. The discharge continued for three and a half months, suddenly ceased for five months, then came on again, lasting nine months; again stopped for two months, and once more recommenced in April last. The urine he brings this morning is of a milk-white colour, with pink and dark-red clots in it. It is said to be copious in quantity, and frequently passed : the clots in it frequently occasion difficulty of micturition. The urine often coagulates, and readily decomposes. No local sympvol, XLV. 
toms externally. He is a pallid lad, and complains of rheumatic pains and diminished appetite.

In later visits I gathered that the morning urine was white in colour, while that passed in the after part of the day was reddish, or soon became so. On November 16th he passed in my presence a large quantity of urine, the colour of which was at the outset brick-red, but towards the close of micturition became lighter and more pink : also a red clot of some size and irregular lobulated form; the colour of this, at first purple, became bright scarlet.

In the intervals when the urine appears to be unaffected he states that it is high coloured, but clear, and less in quantity. Ingestion of flesh or wheaten bread increases the disease.

Microscopic examination of the urine showed the presence of the elements of chyle, chyle-corpuscles of varying size and form, and some red corpuscles of usual size. I have figured and measured some of these objects.

A portion of urine, pinkish, with clots, was put aside in a cool place, and after a while the red corpuscles were found precipitated : the body of the fluid was opaque and nearly white, and on the surface was a thin layer of firm, white substance, which had the appearance of solid, fatty matter.

Instances of the more ordinary forms of chylous urine are not uncommon here. I have by me the notes of two other cases, one of which greatly resembles that last described, and in it the dependence of the opacity and red clots upon the focd is yet more striking. If the man, an adult Parsee, abstains from food for an entire day, the urine becomes clear at once. When chylous, it coagulates, is excessive in quantity, but is not influenced by exercise. The other case referred to is that of a young Hindoo, who has long been the subject of chylous urine. The colour is white, and it contains clots. I possess also the notes of an affection of the scrotum similar to that described in Case 2, only at a much earlier stage, and not accompanied by chylous urine. I found in the fluid discharged from the tubercles the elements 
of a diluted chyle : heated, the fatty matter rose to the surface, and was readily soluble in ether. There is, published in the 'Edinburgh Medical Journal,' January, 1860, a case altogether resembling, as regards the scrotal affection, that narrated above. The writer, an intelligent medical missionary, does not seem to have recognised the milky fluid as chyle, not having, it would seem, carefully examined it. An operation was performed in this instance, without success. A second case is referred to in the same article. In July, 1854, a graduate of the Grant Medical College recorded a case of partial hypertrophy of the scrotum, attended with a peculiar eruption and discharge. 1 I forbear at present from remarking further on this peculiar affection of the lymphatics of the scrotum and its probable connection with elephantiasis of the same part, in order to avoid confusion.

The cases now reported give evidence of a state of the lymphatic system not hitherto recognised. In the first instance the glands are greatly enlarged and their function increased, the vessels connected with them are also dilated, and there is clear proof that this state extends inwards; as high, indeed, as the thoracic duct, since the fluid discharged at the skin of the thigh is not mere lymph, such as ordinary lymphatic vessels carry, but a rich chylous fluid. Of such a fluid the only source can be the terminal lactcals above, the flow or current being reversed on account of the altercd state of the vessels, whose valves arc probably useless. Had the chylous fluid, which in this case pourcd out on the cutaneous surface, been turned upon the urinary mucous tract, we should have had all the phenomena of chylous urine.

In the second case this must, in reality, have occurred. There is a very similar but more marked morbid condition of glands and vessels, and a similar reversal of the flow of chyle; but, in addition, the urine is found to contain chyle, its appearance in that fluid being clearly connected with exacerbation of the local disease.

${ }^{1}$ See the 'Bombay Medical and Physical Transactions' for that year. 
Lastly, in the third case the urine has the characters of that last mentioned, but there is no external local disease. It would be difficult, however, to disprove the possibility of more deeply seated local hypertrophy and dilatation of the lymphatic system; the warrantable presumption is that such really existed.

Hitherto anatomical proof of the accuracy of these views has not been obtained, but many of the phenomena of disease are considered to be satisfactorily explained on grounds not so well founded in reason and fact as those now offered in support of the proposed explanation of chylous-urine disease. The following remarks will, it is submitted, substantiate what is now said.

\section{On the Pathology of the Disease.}

The physical properties of the urine now referred to are well known to most observers. Dr. Prout ${ }^{1}$ mentions the white appearance and spontaneous coagulation as characterising this condition, but the latter feature is by no means invariable, and the colour may be tinted red.

As to the microscopical characters of chylous urine, there is no great uniformity amongst observers; but the points of uncertainty have mostly turned upon the presence or absence of oil-granules and oil-globules. No writer has hitherto recognised the occurrence of chyle-corpuscles in the urine, though Rayer, and more recently Beale, have mentioned the occasional occurrence of small granular cells (Kölliker's nuclei ?).

With respect to the chemical composition of chylous urine, the presence of albumen, more or less perfected, and of fat, is universally recognised, as well as the occasional appearance of fibrine. The salts and extractives have not been

I In this he has been followed by Watson and others. He first accurately described the disease, and gave the name "chylous," afterwards changing the term to "chylo-serous," apparently in accordance with his altered opinions of its nature. 
sufficiently discriminated to allow of satisfactory inference. The only complete analyses of chylous urine accessible to me are those given in 'Beale's Archives,' vol. i, p. 10, two being made by the editor himself, and two others taken from Dr. B. Jones. The qualitative analysis found in the 'Madras Medical Reports' for 1855 furnishes no data for calculation.

Prevailing views of the nature of the disease.-On most occasions, when this part of the subject is treated of, the views of Dr. Prout are brought forward, and adopted wholly or in part. He says, " the chyle, from some derangement in the processes of assimilation, is not raised to the blood standard, and consequently, being unfit for the future purposes of the economy, is, agreeably to a law of the economy, ejected through the kidneys. But these organs, instead of disorganizing or reducing it to the crystallised state, as usual (that is, instead of changing the chyle into the lithate of ammonia), permit it to pass through them unchanged." Dr. Prout was well aware that the adoption of his views necessitated two suppositions, viz., mal-assimilation and coexisting renal derangement, but neither of these is tenable in the face of facts to be presently mentioned. We might also ask, what is the nature of a derangement in an organ which persists for years : can such a derangement be "purely functional"? Dr. Elliotson would regard the affection as renal, ${ }^{2}$ but contents himself with saying the kidneys have been found diseased. Drs. G. Bird and B. Jones also incline to a similar view, but no evidence of renal disease is forthcoming; indeed, it may be wanting, as Beale (l. c.) infers. This author, probably the last who has written on the subject, supposes that the chylous condition of the urine is intimately connected with the absorption of chyle, but how it is so does not appear from his remarks. The view now advanced is that it is rather con-

1 'On Stomach and Renal Diseases,' 5th ed., p. 116.

2 'Med. Times and Gaz.', 1857, p. 288. 
nected with an abnormal distribution of the chyle, which becomes admixed with the urine in a direct manner, and not through abnormal excretion of the chyle, as Prout supposed, or its absorption, as Beale thinks.

We can hardly admit that, as a general feature of the disease, a part of the abnormal constituents, as albumen, fibrine, and corpuscles, is derived from the blood, and the fatty matters from the food. The proposed explanation given further on (i.e., the substitution of lymph for chyle) is equal to account for such varieties.

\section{Circumstances not explicable on the generally received hypotheses.}

1. The frequent sudden appearance, and almost capricious cessation and recurrence, of the symptoms.

2. The absence of a chylous condition of the blood, the absence of uniform or determined kidney disease, and the absence of such constitutional disturbance as would necessarily accompany prolonged derangement of the assimilative processes and renal functions.

3. The very long duration of these symptoms.

To these we may add the well-marked endemic nature of the affection, and its frequent complication with hæmaturia.

Circumstances satisfactorily accounted for on the supposition of a direct admixture of chyle, of various degrees of maturation, with the urine.

1. The above-named peculiarity in the origin and course of the disease.-We may suppose that distension of the delicate lymphatics and lacteals in the lumbar region is at length followed by exudation of their contents at one or more points; or, rupture taking place, a fistulous orifice remains, which gives free exit to the chyle or lymph at times of recurring distension; or an abnormal reservoir ("receptaculum") may be formed, which periodically discharges its contents into the pelvis of the kidney, ureter, or 
bladder. ${ }^{1}$ The cases before related evince that such a condition of the lymphatic vessels, accompanied with enlargement and increased function of the corresponding glands, does occur ; that the flow of chyle may be reversed or regurgitation may occur; and that, with this state, the urine may be chylous. It is possible that the large quantity of chyle often mixed with the urine may be partly derived from the hypertrophied glands.

2. The absence of organic change in the blood or kidney is satisfactorily explained; since, on this hypothesis, their implication is no necessary accompaniment of the symptoms. Also, the absence of marked constitutional derangement beyond what is occasionally witnessed-a debilitated state, dependent on the altered destination of nutritive materials.

This remark applies also to the prolonged duration of such cases.

The frequent complication with hæmaturia (see ' Rayer,' l. c.), is explicable on the assumption of a weakened condition of the walls of the blood-vessels, such as would probably accompany a similar condition of the absorbents, both being indicative of structural idiosyncrasy. ${ }^{2}$

But the following features of chylous-urine disease are still better explained, viz., first, the connection of the symptoms with the digestion of food and stimulus of exertion; and next, the variations observed in the character of the urine in different cases.

It is clear that the rapid formation of chyle in the first case, or its quicker circulation, resulting from exertion or

1 Cruveilhier observes, "The network of lymphatics on the mucous membranes, including the bladder, urethra, \&c., is so superficial that the mercury appears uncovered." ('Descriptive Anatomy,' vol. ii, p. 813.) The lymphatics of the ureter are very numerous.

2 The endemic prevalence of the disease in Mauritius, Bourbon, Brazil, West Indies, Cuba, and, perhaps, we may add, its greater frequency in India or the East, is sufficiently explained on the supposition of this structural idiosyncrasy. I have often been struck with the delicate texture of the walls of vessels seen in the bodies of natives of India. 
whatever stimulates the general circulation of fluids in the body, will be accompanied by an increase of the local changes ; by an increased distension of the varicose lymphatics, or overflow of any part dilated into a kind of receptacle, and the consequent passage of chyle into the urinary passages. The case of fluxes generally is the same-hæmoptysis, hæmatemesis, menorrhagia, \&c.

With regard to the different states of the urine in this affection, it will readily be admitted that, if the abnormal communication between the lymphatics and the urinary passages occur at various parts in the course of the former, the "chylous" condition will also vary accordingly.

I have made a table showing the state of the chyle at three several points in its course, and have annexed some references to published cases of the disease, which will serve as illustrations of the state of the chyle at the time of admixture on each occasion. The principal results are that, when chyle of dense opacity and free from fibrine, causing the urine to resemble milk, is poured out, it is presumable that the admixture takes place at the upper or lower end of the mesentery, and probably with vessels that have not yet passed through the series of mesenteric glands. I am of opinion, however, that fibrine does often really exist in such cases, but is not apparent to the eye (nor could it be chemically detected) from being small in quantity or imperfectly matured. It is also not likely that the lacteals in the early part of their course could communicate directly with the urinary passage.

On the other hand, when the urine rapidly solidifies, and takes on a reddish tinge on exposure to air, or contains white or red clots at the time of expulsion, we may suppose the communication is placed higher up, or with the larger lacteals or thoracic duct itself, possibly opening on the mucous surface of the pelvis of the kidney or commencement of the ureter.

Again, when the urine contains only albumen and fibrine, and little or no fatty matters, as seems occasionally to occur, we are warranted in supposing that at this time (the lacteals 
carrying lymph, and not chyle) it is lymph which has become mixed with it. The observations of Dr. B. Jones confirm this view, as in his case the opaque, fatty condition only was connected with food, the appearance of albumen and fibrine being rather regulated by exertion. The varying condition of the urine in any single case is explicable on the assumption that chyle (itself differing in quality) and lymph, mixed at such times in different proportions, are poured out.

Lastly, two other occasional features of chylous urine, viz., the large quantity of fluid often passed, and its tendency to decomposition, are readily understood in the view now taken. The latter circumstance may be partly owing to the immature state of the albuminous compounds of the chyle.

If, in the above observations, other occasional states have been overlooked, it need not be supposed they contradict what has been said ; too little is known of the normal composition and variations of chyle to permit refinement in comparisons.

The idea of mixing chyle and urine long since occurred to Rayer, and the mixture had a striking likeness to chylous urine. ${ }^{1}$

Proofs of the accuracy of these views. - In confirmation of previous remarks, under this head, it is proposed to consider certain facts which amount to proofs of a strongly presumptive kind. These may be arranged as-1. Chemical. 2. Microscopic.

1. Chemical evidence.-The two chief abnormal ingredients of chylous urine are albumen and fatty matters. With regard to fibrine, it is occasionally absent, and frequently small in amount; in chyle itself the quantity of

1 "En examinant cette urine chyleuse comparativement avec une mélange d'urine saine et du chyle rosé recueillé dans le reservoir de Pecquet, chez un cheval, l'analogie de ces deux liquides, de l'urine chyleuse artificielle et de l'urine chyleuse de l'honme, m'appara des plus frappantes..... Quant aux urines albumino-graisseuses elles ressemblaient une urine dans laquelle on aurait ajouté les élémens organiques du chyle, moins ses globules." ('Mal. des Reins,' t. iii, p. 421.) 
fibrine varies. The salts and extractives of chyle have not yet been sufficiently discriminated to allow of comparison with similar constituents of the urine. Confining, therefore, our observations to the two first-mentioned ingredients, it will at once be obvious that, when present in the urine, they should, in accordance with the hypothesis now advanced, be found in relative proportions similar to those of chyle, since neither is present normally in the renal secretion. It is equally apparent that the quantity of chyle mixed with the urine may greatly vary.

Now, on comparing the analysis of chylous urine and chyle itself, we find that in the former albumen and fat exist in the same proportion as in the latter.

For example, Rees' analysis of chyle gives the following figures :

Fibringer 1000 .

Fibrinous matters . $\quad$ - 3.70

Albuminous matters $\quad . \quad .35 \cdot 16\}$ proportions

Fatty matters . $\quad . \quad 36.01\}$ nearly equal.

The chyle of the cat was found by Nasse to contain-

Fibrine . $\quad . \quad \begin{gathered}\text { Per } 1000 \\ 1.3\end{gathered}$

Albumen $^{1}$. $\quad . \quad$. $\quad 33.25$ ? proportions

Fat . . . . 3275 nearly equal.

So that in well-elaborated chyle these ingredients are found in about equal proportions ; in urine mixed with chyle the relative quantities should be the same.

Such is sometimes the case. Dr. L. Beale ${ }^{2}$ analysed a specimen of chylous urine, and found-

Per 1000.

Albumen . $\quad$ - . $\quad 130\}$ proportions

Fatty matters $\quad . \quad$. $\quad 13.9\}$ nearly equal.

1 The numbers are, albumen and extractives, $48 \cdot 9$ per 1000 . In order to obtain the quantity of albumen alone, $I$ have deducted the extractives, taking the numbers Rees gives for them, viz. 15.65: there then remains the amount indicated above.

2 Loc. cit., p. 12. 
These numbers appear to me to correspond far too closely to be the result of mere accident ; and, admitting this, the inference $I$ have made is natural and logical. The actual quantity of albumen and fat in Beale's case indicates a dilution of chyle with urine to the extent of upwards of two thirds.

In similar circumstances the composition of chyle must always be the same, but both differ at times: so does the composition of chylous urine. I give another example. Nasse analysed the chyle of the horse, and found only half the quantity of fatty matters, as compared with albumen.

\begin{tabular}{|c|c|c|}
\hline & & Per 1000. \\
\hline Fibrine & - & $\cdot \quad 75$ \\
\hline Albumen & . & . 31.00 proportion, 2 of albumen \\
\hline Fat & . & $15.00\}^{2} \quad$ and 1 of fat. \\
\hline
\end{tabular}

Dr. B. Jones furnished two analyses of chylous urine, the only others I know of, and has recorded this result :

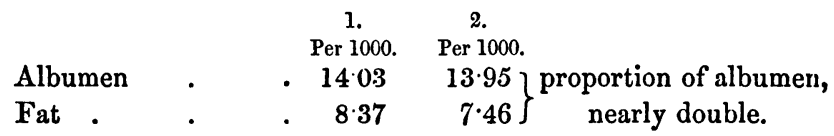

In this instance, as in the first, the correspondence is striking enough to warrant close attention, and confirms the inference drawn from the first example given. This comparative mode of viewing the subject I conceive to be the most legitimate; and, bearing in mind the normal variations chyle is liable to, I find no contradiction of an insuperable nature in these two cases. If this be granted, the explanation I propose appears to represent the truth. No other fluid than chyle has the same composition, and, so far as I am aware, no ingredients of chylous urine are not found in either this fluid or the urine itself. (See the Table at the end.)

2. Microscopical evidence.-It may first be remarked, under this head, that the presence of a "molecular base" in chylous urine has already been established, and the 
occasional presence of minute oil.globules, such as occur in chyle.

Granular corpuscles have also been noticed, as before stated, but in no instance have true chyle-corpuscles been recognised. The presence of these would necessarily settle the question of the presence of chyle. In Case No. 3, I have ascertained their undoubted existence in considerable numbers; and they were also found in the urine of Case No. 2. In the former they were of various form and sizeminute granules; round granular corpuscles, whose walls were not visible; some elongated, some of larger size, with distinct cell-wall, starred, or furnished with the characteristic processes; others still larger, varying in diameter up to $\frac{1}{2000}$ in., the smaller ranging from $\frac{1}{6000}$ to $\frac{1}{3500}$ in. A few red blood-corpuscles were seen, and cells larger than these, with irregular margins, but clear. In a specimen examined immediately after being passed, I found granular masses of rounded form ; pale, clear corpuscles, which appeared to be red blood-cells, altered in shape, elongated, curled up, and variously bent; others were clearer, a little larger, tuberculated, and having incipient processes attached. It was easy to see that all were not red blood-cells, or, indeed, identical with any found in the blood. In Case No. 2 the urine contained, besides red corpuscles, many granular cells much larger than these, and showing, on addition of acetic acid, three or four nuclei.

(Quoted from clinical records.)

The microscopical examination of these urines, then, gave positive proof of the admixture of a fluid dissimilar to blood and similar to chyle, as chemical analysis shows. With regard to the negative results of others, it does not contradict, but only falls short of, what I have witnessed. Nor can it be objected that my cases were not fair examples of the disease. No inconsiderable item in the evidences is derived from the determination of a molecular base. Beale, Priestley, and others, have established this. In further examinations of chylous urine it may be advisable to examine any sediment that may form, and take other precautions to ascertain the existence or non-existence of 
chyle-corpuscles. Kölliker ${ }^{1}$ remarks, " a considerable variation exists, and a milk-white chyle is not always rich in corpuscles."

I might now proceed to show that the microscopic variations of chylous urine are explicable, like the chemical, on the supposition that chyle became mixed with urine at different points in different cases, but shall content myself with summing up the peculiarities of chyle, which, if detected in the abnormal urine, would not only establish the presence of that fluid, but also assist in determining the locality whence it may have been derived. Kölliker ${ }^{2}$ finds in chyle immeasurably fine granules (molecular base); nuclei of $\frac{1}{10,000}$ to $\frac{1}{5000}$ in. in diameter; chyle-corpuscles, $\frac{1}{4000}$ to $\frac{1}{800}$ in., or larger, and red corpuscles. In the larger mesenteric trunks the chyle-corpuscles first appear, and are then imperfectly formed ; size, $\frac{1}{5000}$ to $\frac{1}{3200}$ in. Nearer the thoracic duct, they become more numerous and much larger, and some may be seen dividing. In the last-named locality the larger corpuscles disappear, and ordinary chyle-cells are seen. The presence of numerous free nuclei would indicate early admixture of chyle; the very large corpuscles, with several nuclei, \&c., a later ; and the presence of well-formed chylecorpuscles only, a derivation of the chyle from the thoracic duct.

With regard to a phenomenon observed in the chyle derived from the thigh and scrotum, in Cases No. 1 and 2, I endeavoured to witness under the microscope the change of colour there observed, but did not succeed. The change is possibly chemical, for Rees has found a considerable quantity of oxide of iron in the albumen of chyle, which latter, in the analysis, would be mixed with the corpuscles.

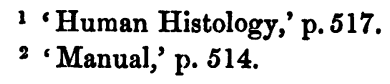


Chemical Analysis.

\begin{tabular}{|c|c|c|c|c|c|c|}
\hline \multicolumn{3}{|c|}{ Chyle. } & \multicolumn{4}{|c|}{ Chylous Urine. } \\
\hline $\begin{array}{l}\text { Water } \ldots . . . . \\
\text { Fibrine ...... } \\
\text { Albumen .... } \\
\text { Fatty matters } \\
\text { Extractives } \\
\text { Salts ......... }\end{array}$ & $\begin{array}{r}\text { Nasse. } \\
905 \cdot 70 \\
1 \cdot 30 \\
133 \cdot 25 \\
32 \cdot 70 \\
15 \cdot 65 \\
1] \cdot 40\end{array}$ & $\begin{array}{r}\text { Rees. } \\
902 \cdot 37 \\
3 \cdot 70 \\
35 \cdot 16 \\
36 \cdot 01 \\
15 \cdot 65 \\
7 \cdot 11\end{array}$ & \multicolumn{2}{|c|}{$\begin{array}{l}\text { Water } \ldots . . . \\
\text { Urea .......... } \\
\text { Albumen .... } \\
\text { Fatty matters } \\
\text { Ext. and uric } \\
\text { Salts .......... }\end{array}$} & $\begin{array}{r}\text { Beale. } \\
947 \cdot 40 \\
7 \cdot 73 \\
13 \cdot 00 \\
13 \cdot 90 \\
11 \cdot 66 \\
6 \cdot 31\end{array}$ & $\begin{array}{l}\text { First example } \\
\text { Albumen and fat } \\
\text { in nearly equal } \\
\text { proportions. }\end{array}$ \\
\hline \multirow[b]{2}{*}{$\begin{array}{l}\text { Water } . . . . . \\
\text { Fibrine ...... } \\
\text { Albumen .... } \\
\text { Fatty matters } \\
\text { Extractives } \\
\text { Salts .......... }\end{array}$} & \multirow[b]{2}{*}{$\begin{array}{r}\text { Nasse. } \\
935 \cdot 00 \\
\cdot 75 \\
31 \cdot 00 \\
15 \cdot 00 \\
6 \cdot 25 \\
8 \cdot 00\end{array}$} & \multirow{2}{*}{\multicolumn{2}{|c|}{ 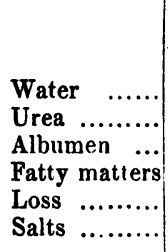 }} & \multicolumn{2}{|c|}{ B. Jones. } & \multirow[b]{2}{*}{$\begin{array}{l}\text { Second exam- } \\
\text { ple. Albumen } \\
\text { and fat: the albu- } \\
\text { men being double } \\
\text { in quantity. }\end{array}$} \\
\hline & & & & $\begin{aligned} 1 \\
955 \cdot 58 \\
13 \cdot 26 \\
14 \cdot 03 \\
8 \cdot 37 \\
\cdot 75 \\
8 \cdot 01\end{aligned}$ & \begin{tabular}{r}
\multicolumn{1}{c}{2} \\
$943 \cdot 13$ \\
$24 \cdot 06$ \\
13.95 \\
$7 \cdot 46$ \\
$\cdot 60$ \\
$10 \cdot 80$
\end{tabular} & \\
\hline
\end{tabular}

Cases of Chylous Urine, arranged in physiological series.

First Series.-Chyle from the lacteal vessels.

Characters. - Albumen plentiful; generally no coagulum or fibrine; molecular base abundant; oil-globules of varying size; free nuclei.

Examples.-Rayer, 1. c., pp. 395, 403 (in this case the blood was also affected); G. Bird, 'Urin. Dep.', pp. 390, 394 ; Bramwell's case, ' Ed. Med. Jour.,' 1858, p. 714.

Cases in which fibrine is at all times totally wanting are of doubtful occurrence.

Second Serirs.-Chyle from the mesentery.

Characters.-Albumen and molecular base diminished; oilglobules fewer. Fibrine appears. Free nuclei few. Imperfect chyle-corpuscles. The colour is white, and coagulation imperfect.

Examples.-Rayer, 1. c., p. 388; Elliotson, 'Med. Times and Gaz.,' 1857, p. 288 ; Beale's case, l. c.; Pearse, 'Mad. Med. Rep.,' 1855 ; Prout, l. c. ; cases narrated in Morehead, 'Clin. Res.,' vol. ii. Own cases.

1 In the original analysis the extractives are estimated along with the albumen. In order to obtain the quantity of the latter, the extractives have to be subtracted, and, taking the analysis of Rees, which closely corresponds, I subtracted $\mathbf{1 5 . 6 5}$ from the figures of both constituents combined, viz., from $48 \cdot 9$. Thus, for albumen, we have 33.25 . 
Third Series.-Chyle from the receptaculum chyli and thoracic duct.

Characters.-Fibrine abundant. Chyle-corpuscles more numerous, more perfect, and of larger size. No free nuclei, or few. Incipient red corpuscles. Coagulation quick and complete, but varying.' A decided red tinge on exposure to air. Fat floats on serum.

Examples.-Rayer, 1. c., pp. 390, 427; Priestley, 'Med. Times and Gaz.,' 1857, p. 382 ; Elliotson, l. c., p. 288 ; B. Jones, 'Phil. Trans.,' 1850 , p. 651 . Own cases.

Fourth Series.-Lymph urine.

Characters.-The urine coagulates; albumen is present; corpuscles few, but no fatty matter, or a few granules.

I add this series, believing in its real existence. The urine would have the above characters in the intervals of digestion or after fasting. In this case, also, the fibrine may seem to be absent, and even albumen not to be detected by the usual tests. (Thudichum, 1. c., p. 240.)

Examples.-Dr. B. Jones's case, at intervals. Goodeve's case, 'Trans. of Med. and Phys. Soc. Calcutta,' vol. viii :-An aged female : urine, when clear, "occasionally loaded with transparent jelly, which, floating in it, was not easily distinguishable from the fluid itself until the contents of the receiving vessel were poured into another pan, when it became evident that the excretion was almost entirely composed of solid matter." "There was not the slightest tendency to dropsy in this case." The disease had lasted six months, and had all the features of chylous urine excepting the above: the patient was a large eater, particularly of animal food.

1 Carpenter, 'Human Physiology,' 5th ed., p. 123, " On Chyle :"-“ It is curious, however, that considerable differences in the perfection of the coagulation, and in its duration, should present themselves in different experiments. Sometimes the chyle sets in a jelly-like mass, which, without any separation into coagulum and serum, liquefies again at the end of half an hour, and remains in this state." The admixture of urine may be supposed to further modify this process. 


\section{DESCRIPTION OF PLATE III.}

Fig. I.-Case 1. Lymph (chyle?) from the thigh, two hours after removal. Contents :

a. Groups of minute granules; a few masses of granules; a hazy tint.

b. Red blood-corpuscles, some apparently dividing; oil-globules (?).

c. Granular corpuscles, 3500 to $\frac{1}{2000}$ in. in diameter, the larger being nucleated.

Fig. II.-Case 2. Varicose lymphatics and hypertrophied lymphatie glands, accompanied with external diseharge of chyle and perfectly chylous urine.

Fig. III.-Case 2. Lymph (chyle?) from the scrotum. Contents of the clot:

Molecular base : few granules.

a. Red blood-corpuscles, $\frac{1}{4000}$ to $\frac{1}{6000}$ in. in diameter, some granular and starred.

b. Corpuscles rather larger ( $\frac{1}{3800}$ to ${ }_{2666}$ in.), but like them ; colour less decided, and margins less irregular; numerous.

c. Numerous nuclei, varying in size ( $\frac{1}{3800}$ to $\frac{1}{2500}$ in.); some mulberryshaped, some flattened.

d. White blood-corpuscles (?), very few ; $\frac{1}{2700}$ in.; fibrinous striæ.

Fig. IV.-From chylous urine. Chyle-corpuscles, of various forms and sizes, $\frac{13}{2300,} \frac{1}{3200}$, and $\frac{1}{3000}$ in. in diameter. A few red corpuscles. 


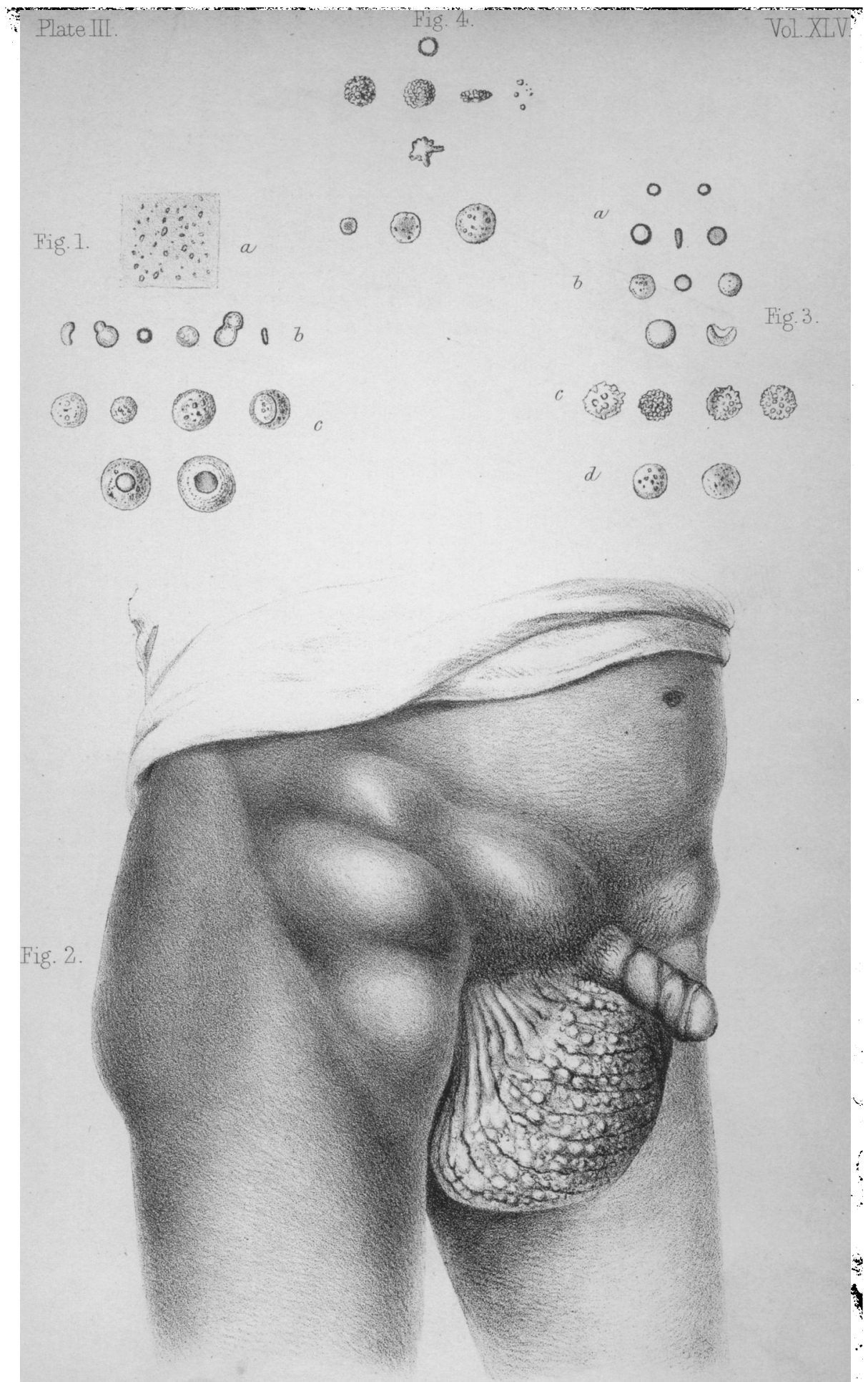

